\title{
HYPERFINE STRUCTURES IN THE FIRST SPECTRA OF KRYPTON AND XENON
}

\author{
By C. J. Humphreys
}

ABSTRACT

The stronger arc lines of krypton and xenon have been examined for hyperfine structures. Methods of observation include the use of a Hilger Fabry-Perot interferometer having quartz plates of $6 \mathrm{~cm}$ aperture, a -number of fixed étalons, and two quartz Lummer-Gehrcke plates. The relative advantages of these two types of interferometers are considered. The results obtained by different methods show very satisfactory agreement. Structures of the following lines have been measured: Krypton, 5,570.2890, 7,685.2472, 8,059.5053, 8,104.3660, 8,281.042, and 8,508.8736 A; xenon, 4,193.5296, 4,500.9772, 4,734.1524, 8,231.6348, $8,409.190$, and $8,819.412 \mathrm{~A}$.

The observed complex lines in the two spectra are not spectroscopically analogous. No definite numerical regularities in the spacing of components, such as have been reported in the case of neon, have been observed. Five of the six complex xenon lines are due to combinations with the low ${ }^{3} P_{2}$ level. The regularities in the fine structures of neon are discussed. The satellites of neon lines are supposed to be due to Ne isotope 22 . Krypton and xenon are reported to have 6 and 9 isotopes, respectively, and the fine structure might be expected to be more complicated.

The relative abundance of isotopes of odd atomic weight in krypton and xenon leads to the consideration of the possibility that the satellites sufficiently separated for observation may be due to the nuclear moment of these odd isotopes, in accordance with a suggestion advanced by Schüler to explain the hyperfine structures in mercury. It is hoped that, by operating the sources at low temperatures, and using still higher resolving power, additional structures may be observed.

\section{CONTENTS}

I. Introduction

II. Experimental procedure.

III. Reduction of observations 458

IV. Discussion of results

\section{INTRODUCTION}

The examination of the hyperfine structures in the spectra of krypton and xenon has been undertaken in connection with the complete investigation of these spectra. The progress of this investigation which had its origin in the suggestion that some line from the krypton spectrum might be more suitable as a primary standard of wave length than the red line of cadimum, has been reported in earlier papers. The description and classification of the first spectra of krypton and xenon are contained in two papers by Meggers, de Bruin, and Humphreys. ${ }^{1}$ Interference measurements of the wave lengths of the more intense lines have been published by Humphreys. ${ }^{2}$ The examination of the interference patterns, made in connection with the precise measurement of wave lengths by aid of Fabry-Perot fixed 
étalon interferometers, clearly indicated that certain of the lines of xenon were complex. The resolving power employed was not sufficient, however, for a satisfactory measurement of the patterns. The use of apparatus of higher resolving power has now permitted the measurement not only of the xenon fine structure patterns, but also those of a number of krypton lines. This note is to be regarded as preliminary, however, to the report of a more extended investigation. Hyperfine structures have been actually observed for only a relatively small number of $\mathrm{Kr}$ and Xe lines. If, as is generally supposed, the complexity in spectral lines of these gases is due to isotopes, satellites should be expected in the case of all lines intense enough to show them. No structural similarities have been observed between spectroscopically analogous lines in the two spectra. Thus the lines of krypton, arising from the same term combinations as the complex lines of xenon, are apparently free of structure, and vice versa. These facts lead to the belief that possibly other lines of both spectra are complex but still unresolved. When the investigation is resumed it is planned to use still higher resolving power and to operate the light sources at lower temperatures to improve the sharpness of the lines.

\section{EXPERIMENTAL PROCEDURE}

The apparatus and the experimental arrangement used in this investigation were essentially as described in the report on the interference measurements. ${ }^{3}$ At the beginning of the experiments it was expected to immerse the tubes used as sources of radiation in liquid air, in the hope of sharpening the lines by reducing the Doppler motions of the radiating atoms. This procedure had been successful in the case of experiments with neon. ${ }^{4}$. With this idea in mind pyrex tubes were designed with the capillary portion shaped to permit of end-on emission of radiation when immersed in an unsilvered Dewar flask. Attempts to use such xenon-filled tubes in this manner were not successful, however, because the discharge could not maintain a sufficiently high temperature to prevent condensation or freezing of the gas. Tubes of this design proved to be useful, however, in connection with observations made with Lummer-Gehrcke plates in which case end-on illumination is the most economical method of using the available radiation. For the examination of the krypton spectrum a tube obtained from Robert Götze in Leipzig was used. This tube, designed especially for end-on use, had a very fine capillary and emitted a much stronger radiation than any other tubes available. The use of the end-on tube caused certain of the krypton lines to appear reversed. The reversals could be eliminated and thus distinguished from genuine fine structures by repeating the observations with a side-on exposure.

A Hilger interferometer, having crystal quartz plates of $60 \mathrm{~mm}$ available aperture, and permitting variable separation of the plates up to $100 \mathrm{~mm}$ was used in connection with the glass $E_{2}$ spectrograph in making some of the first exposures. Among a large number only two satisfactory spectrograms were thus obtained. The apparatus was not sufficiently stable to maintain the adjustment of the plates during an exposure time of from two to five hours necessary with the

Humphreys, B. S. Jour. Research, 5, p. 1041; 1930.

- E. Thomas and E. J. Evans, Phil. Mag., 10, p. 128; 1930. 
relatively faint sources of radiation available. It was; therefore, found advisable to resort to the fixed étalon method for the examination of those lines suited to observation with a Fabry-Perot interferometer. A pair of glass plates of $40 \mathrm{~mm}$ diameter were resilvered, by the cathode sputtering process, with as heavy a coat as could be used consistent with a reasonable exposure time. These plates were used with 15 or $20 \mathrm{~mm}$ separators for observing the hyperfine structures of infra-red xenon lines. Observations of a portion of the xenon spectrum were also repeated using a set of étalons which were constructed to accommodate the large quartz plates.

The observations on the xenon lines were repeated with LummerGehrcke plates. This method disclosed some additional complex lines and additional satellites in the structures already known. It also revealed the complex lines of krypton which had not been found by aid of Fabry-Perot interferometers, a result which is to be accounted for by the fact that the complex infra-red lines are of moderate intensity and in most cases lie close to very strong lines. With the heavy silvering on the interferometer plates requisite for high resolving power, it is doubtful if the satellites of these lines could be recorded with reasonable exposures, using Fabry-Perot étalons. It was found necessary in the examination of the krypton lines, 5,570 and 5,870 A, to use the Lummer-Gehrcke plates in connection with the Anderson grating in order that the spectral dispersion might be sufficient to permit a distinction to be drawn between genuine satellites and faint lines lying close to the strong lines. Observations in the infra-red region were also repeated using the grating as the dispersing instrument.

Two quartz Lummer-Gehrcke plates were available, the respective lengths and thicknesses being 130 by $4.24 \mathrm{~mm}$ and 190 by $6.24 \mathrm{~mm}$. The attached prisms were of the form designed by Twyman to permit the incident light to enter parallel to the plate faces and allow the sources to be mounted in a line along the axis of the spectrograph. ${ }^{5}$ The Lummer-Gehrcke plates were mounted on the supporting stand used with the étalon mountings with the same arrangement of optical parts, only slight adjustments being necessary when substituting one form of interferometer for the other. The arrangement, which has been described in the previous publication, ${ }^{6}$ makes use of two lenses, one to transform the radiation incident upon the interferometer into a beam of parallel rays, and the other an achromatic lens, in this case of $50 \mathrm{~cm}$ focal length, to project the fringe system upon the slit of the spectrograph. The Lummer-Gehrcke plates were mounted with the surfaces in the horizontal position so that the system of approximately straight horizontal fringes was at right angles to the slit. Although the mounting permitted the utilization of the interference systems from both the upper and lower surfaces of the plate, only one set of fringes was used at a time. ${ }^{7}$ Since the Lummer-Gehrcke plates were of quartz which is doubly refracting it was necessary to pass the

\footnotetext{
This condition is not realized in the strictest sense, especially if an end-on tube, which effectively reduces the incident light to a narrow pencil, is used. If a fired direction of emergence from the Lummer-Gehrcke plate, parallel to the optic axis of the spectrograph, is maintained, the direction of incidence will depend upon the wave length, because if the varation of the indes of refraction of the plate material with wave variation in direction of incidence is small it must be taken into account in selecting a particular spectral region for study.

Humphreys, B. S. Jour. Research, 5, p. 1041; 1930.

7 The number of fringes which can be photographed obviously depends upon the magnification of the projected interference system in relation to the length of the slit, which is governed by the focal length of the projecting lens.
} 
incident radiation through a nicol prism in order to eliminate one of the two interference systems which would be formed if the light were not polarized.

A further advantage in the use of polarized light, which is realized also with plates of isotropic material, is increased resolving power, provided the proper orientation of the plane of polarization is chosen. It has been pointed out that the maximum resolving power is obtained with the Lummer-Gehrcke plate if the intensities of successive interfering beams emergent from the surface are equal. While complete realization of this ideal condition is not possible, it is known that the least diminution in intensity of successive beams occurs when the ratio of reflected to transmitted light at the inner surface is a maximum, a condition which is realized for a given angle of incidence if the light is polarized so that the direction of vibration or electric vector is parallel to the plate surface and at right angles to the direction of propagation of the radiation. In practice, quartz Lummer-Gehrcke plates are cut with the optic axis parallel to the surface or nearly so and at right angles to the greatest dimension of the plate. Consequently, incident radiation polarized in the most advantageous direction, has its direction of vibration parallel to the optic axis and is transmitted as the extraordinary radiation. The requisite orientation of a nicol prism of the usual type is to place it so that the short diagonal of the rhomb-shaped end face is parallel to the plate surface.

The relative advantages of the different forms of interference apparatus used may be considered briefly. In the examination of any complex spectral line it is desirable that the spacing of the components in any one order of the interference pattern be as large as possible without overlapping of successive orders. Since the realization of this condition depends entirely upon the choice of the proper retardation, the Fabry-Perot interferometer with variable separation of plates would seem to be the ideal instrument. The difficulties we have encountered because of the lack of stability have been mentioned, and it seems doubtful if the instrument, at least as now designed, can be used with faint sources where good adjustments must be maintained for several hours. The fixed étalon mounting is remarkably stable, and not affected by slight mechanical disturbances. We have found that the condition of parallelism between the plates has in many instances been maintained for a number of days without adjustment. The simplicity of design and relative ease of construction of the étalons and mountings renders this type of apparatus available for general laboratory use. The Lummer-Gehrcke plate, having its surfaces ground parallel, requires no adjustment to make it ready for use other than to place it in the correct position with respect to the other parts of the apparatus. The range of usefulness of a given plate is, however, restricted to the study of those structures for which the retardation corresponds to a satisfactory dispersion of the components. A single Lummer-Gehrcke plate is essentially equivalent to a pair of Fabry-Perot plates used with one fixed étalon. It is obvious that if a series of étalons is available a suitable retardation may be chosen for any wave length in the accessible region or for a pattern of any separation within the limits which can be set for examination by interferometer methods,. The resolving power may 
also be altered at will by changing the retardation or the reflecting power.

Under the best conditions of illumination the Lummer-Gehrcke plate yields a more intense interference pattern than the Fabry-Perot interferometer. This is mainly due to the loss of light in the latter, due to reflection and absorption at the silver surfaces. For a given retardation the practical resolving power of a Lummer-Gehrcke plate is superior to that of a Fabry-Perot étalon interferometer unless the reflecting power is exceedingly high. This is especially true in the violet and ultra-violet regions where the reflecting power of metallic films begins to fall off.

The Lummer-Gehrcke plate is reported to be extremely sensitive to temperature variation. Hansen ${ }^{8}$ has calculated that a change of $5^{\circ} \mathrm{C}$. is sufficient to cause a shift of a given fringe into the position of the adjacent fringe. The Fabry-Perot étalon is affected in a number of ways due to changes of temperature or pressure. The index of refraction of air may change, and the variation in the length of the invar separators is not entirely negligible. We have used both instruments in a basement laboratory in which the temperature was fairly steady but not controlled. No difficulty has been experienced provided the temperature variations did not exceed $0.1^{\circ}$ to $0.2^{\circ} \mathrm{C}$.

The reduction of observations obtained by aid of an étalon is much less laborious than those obtained with a Lummer-Gehrcke plate, because of the simple relationship $\lambda p=2 e$, which exists in the former case between wave length, retardation, and plate separation. This formula is not only easy to apply, but permits extremely accurate comparisons of wave length. The corresponding formula for the Lummer-Gehrcke plate involves the index of refraction of the plate material which must usually be interpolated or extrapolated for the wave length being observed. It can be used successfully only for the determination of the separation of satellites.

In any case the method chosen should be suited to the particular structure under observation. The xenon line 4,501 A for which the fine structure pattern has a total width of $0.06 \mathrm{~A}$, is most satisfactorily observed with an étalon of $10 \mathrm{~mm}$ thickness, but both of the LummerGehrcke plates available have yielded excellent results in the study of this structure. On the other hand, the pattern of four strong components of $8,231 \mathrm{~A}$, having a separation of $0.085 \mathrm{~A}$ has been clearly resolved only with étalons ranging from 15 to $25 \mathrm{~mm}$ in thickness. ${ }^{9}$ In general, the Fabry-Perot étalon method is recommended for the study of structures in the visible and infra-red regions where the width of the pattern is $0.1 \mathrm{~A}$ or less. A Lummer-Gehrcke plate of the conventional size is best adapted to the study of wide patterns in the visible and infra-red regions and if of transparent material to general use in the ultra-violet. Wherever possible, the observation of a structure by both methods is desirable.

8 Hansen, Zeits. for wiss. Phot., 23, p. 17; 1925.

- The change in wave length, $\Delta \lambda$, corresponding to the displacement in the interference pattern between one maximum and the corresponding maximum in the adjacent order, varies directly as the square of the wave length for either type of interferometer, and inversely as the retardation. The ratio of the separation of a satellite from a line to this displacement of adjacent orders should be large for most satisfactory observation up to the point of actual overlapping. The ratio can be increased for a given wave length only by increasing the retardation. The practical limitations on the thickness of Lummer-Gehrcke plates sets a lower limit on the closeness of patterns which may be thus observed, which increases rapidly as we go to longer wave lengths. 


\section{REDUCTION OF OBSERVATIONS}

The computation of the wave lengths of the satellites in the observed patterns was carried out in the case of observations made with étalons according to the method described in the paper ${ }^{10}$ in which interference measurements in these spectra were discussed. The values of the xenon wave lengths reported in the earlier paper were used as standards. The method requires the precise determination of the separation, $e$, of the plates and the retardation, $p$, expressed as the number of wave lengths in a path equal to $2 e$.

These quantities then permit the solution of the equation

$$
\lambda=\frac{2 e}{p}
$$

The corresponding equation applying to the Lummer-Gehrcke plate is

$$
\lambda=\frac{2 e}{p} \sqrt{\mu^{2}-\cos ^{2} E}
$$

in which $\mu$ is the index of refraction and $E$ is the angle between the emergent beam and the plate surface. The retardation, $p$, is not capable of direct determination. We calculate instead the quantity $\Delta \lambda$ which is the increment in wave length corresponding to the displacement between adjacent fringes, that is $\Delta \lambda$ is evaluated when $p=1$. It may be shown that

$$
\Delta \lambda=\frac{\lambda^{2} \sqrt{\mu^{2}-\cos ^{2} E}}{2 e\left(\mu^{2}-\cos ^{2} E-\lambda \mu \frac{\partial \mu}{\partial \lambda}\right)}
$$

'This reduces to

$$
\Delta \lambda=\frac{\lambda^{2} \sqrt{\mu^{2}-1}}{e\left(\mu^{2}-1-\lambda \mu \frac{\partial \mu}{\partial \lambda}\right)}
$$

when the interference pattern corresponding to nearly grazing emergence is used. The separation of any satellite from the main component of a pattern is given by

$$
\delta \lambda=f \cdot \Delta \lambda
$$

where $f$ is determined from the measurements of the observed interference pattern. For the precise evaluation of $f$, it is necessary to observe the complete interference pattern formed by the radiation emerging from both plate surfaces. If the respective distances between fringes of the same order on opposite sides of the central dark portion of the pattern are given by $D_{1}, D_{2}, D_{3}$, etc., and if $D_{81}$, $D_{s_{2}}, D_{s_{3}}$, are the corresponding differences between the fringes due to a given satellite

$$
f=\frac{D_{1}^{2}-D_{s_{1}}^{2}}{D_{2}^{2}-D_{1}^{2}}=\frac{D_{2}^{2}-D_{s_{2}}^{2}}{D_{3}^{2}-D_{2}^{2}}, \text { etc. }
$$

The detailed treatment of the theory of the Lummer-Gehrcke plate has been given by several writers, among whom Hansen ${ }^{11}$ and 
Simeon ${ }^{12}$ may be mentioned. The second article referred to contains an excellent bibliography. In the present investigation, only half of the interference pattern was observed. A linear interpolation method was used to determine the values of $f$, which, while not strictly rigorous, is in the present instance as good as the measurements justify. The method which is due to MacNair ${ }^{13}$ may be understood from a study of the figure.

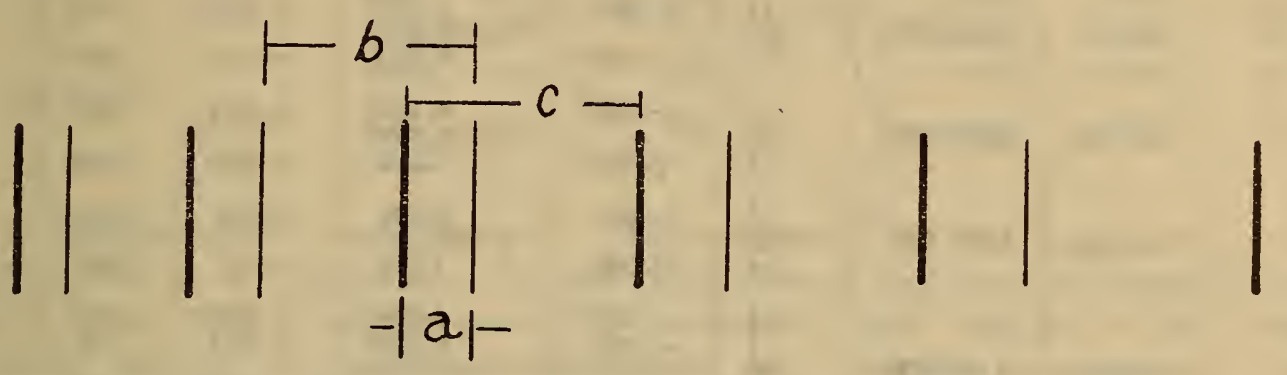

The values of $f$ are computed by aid of the formula,

$$
f=\frac{a}{\frac{b+c}{2}}
$$

The calculation is repeated for successive orders in a given fringe system and should give essentially constant values of $f$.

\section{DISCUSSION OF RESULTS}

The results of the investigation are summarized in Tables 1 and 2. In addition to the average values of $\delta \lambda$, the values of $\delta \nu$, and of $\frac{\delta \nu}{\nu}$ have been assembled in the hope of finding possible regularities. The relative intensities of the satellites are estimated by taking for the main components the values of the intensities of the respective lines to which they belong as given in the published descriptions of the first spectra of krypton ${ }^{14}$ and xenon..$^{15}$ The hyperfine structures of a number of the xenon lines have been analyzed by both of the two methods described. A satisfactory check has been obtained, especially in the case of those lines in the visible spectrum for which the satellite separations were suitable for observation with a LummerGehrcke plate. Table 3 gives a comparison of the observations made on the lines 4,501 and 4,734 A. It is to be noted, however, that in all cases except one the probable error of the arithmetical mean of individual observations made by a single method is less than the corresponding difference between the mean result obtained by the two methods. The exceptional case, that of the satellite on the short wave length side of 4,734 , is to be regarded as accidental, because, of all the satellites measured, this was the least well resolved. We believe that this comparison is significant in any consideration of the accuracy of measurement of fine structures by a single type of interferometer.

12 Simeon, J. Sci. Inst. 1, p. 296; 1924.

13 MacNair, Phil. Mag., 2, p. 613; 1926.

14 Meggers, deBruin, Humphreys, B. S. Jour. Research. (In press.)

is Meggers, deBruin, Humphreys, B. S. Jour. Research, 3, p. 129; 1929. 
TABLE 1.-Krypton hyperfine structures

\begin{tabular}{|c|c|c|c|c|c|c|}
\hline $\begin{array}{c}\text { Combina- } \\
\text { tion }\end{array}$ & $\lambda$, air & Intensity & $\begin{array}{c}\delta \lambda \\
\text { Lummer- } \\
\text { Gehrcke } \\
\text { plates }\end{array}$ & $\nu$, vacuum & $\delta \nu$ & $\frac{\delta \nu}{y} \times 10^{3}$ \\
\hline $1 s_{5}-2 p_{3}$ & $5,570.2890$ & $\begin{array}{r}50 \\
2,000\end{array}$ & -0.0333 & $\begin{array}{r}7.5263 \\
17,947.4190\end{array}$ & +0.1073 & 598 \\
\hline $1 s_{2}-2 p_{1}$ & $7,685.2472$ & $\begin{array}{r}15 \\
400 \\
12\end{array}$ & $\begin{array}{l}-.0671 \\
+.0724\end{array}$ & $\begin{array}{r}8.4817 \\
13,008.3682 \\
8.2457\end{array}$ & $\begin{array}{l}+.1135 \\
-.1225\end{array}$ & $\begin{array}{l}872 \\
942\end{array}$ \\
\hline $1 s_{3}-2 p_{4}$ & $8,059.5053$ & $\begin{array}{r}6 \\
100 \\
8\end{array}$ & $\begin{array}{r}-.0653 \\
+.0571\end{array}$ & $\begin{array}{r}4.4034 \\
12,404.3030 \\
4.2151\end{array}$ & $\begin{array}{l}+.1004 \\
-.0879\end{array}$ & $\begin{array}{l}809 \\
709\end{array}$ \\
\hline $1 s_{2}-2 p_{3}$ & $8,281.042$ & $\begin{array}{r}8 \\
200 \\
6\end{array}$ & $\begin{array}{l}-.097 \\
+.100\end{array}$ & $\begin{array}{r}2.603 \\
12,072.461 \\
2.316\end{array}$ & $\begin{array}{l}+.142 \\
-.145\end{array}$ & $\begin{array}{l}1168 \\
1201\end{array}$ \\
\hline $1 s_{2}-2 p_{4}$ & $8,508.8736$ & $\begin{array}{r}4 \\
1 \\
200 \\
6\end{array}$ & $\begin{array}{l}-.0907 \\
-.0631 \\
+.0820\end{array}$ & $\begin{array}{r}9.3380 \\
9.2999 \\
11,749.2128 \\
9.0996\end{array}$ & $\begin{array}{l}+.1252 \\
+.0871 \\
-.1132\end{array}$ & $\begin{array}{r}1066 \\
741 \\
964\end{array}$ \\
\hline
\end{tabular}

TABLE 2.-Xenon hyperfine structures

\begin{tabular}{|c|c|c|c|c|c|c|c|c|}
\hline$\underset{\text { tion }}{\text { Combina- }}$ & $\lambda$, air & $\begin{array}{l}\text { Inten- } \\
\text { sity }\end{array}$ & $\begin{array}{l}\delta \lambda \\
\text { Fabry- } \\
\text { Perot } \\
\text { etalons }\end{array}$ & $\begin{array}{c}\delta \lambda \\
\text { Lummer- } \\
\text { Gehrcke } \\
\text { plates }\end{array}$ & $\begin{array}{c}\delta \lambda \\
\text { flnal value }\end{array}$ & $\nu$, vacuum & $\underset{\mathrm{cm}^{-1}}{\delta \nu}$ & $\frac{\delta v}{v} \times 10^{8}$ \\
\hline $1 s_{5}-4 u$ & $4,193.5296$ & $\begin{array}{r}3 \\
30 \\
3\end{array}$ & & $\begin{array}{r}-0.016 \\
+.018\end{array}$ & $\begin{array}{r}-0.016 \\
+.018\end{array}$ & $\begin{array}{r}9.658 \\
23,839.567 \\
9.465\end{array}$ & $\begin{array}{r}+0.091 \\
-.102\end{array}$ & $\begin{array}{l}382 \\
428\end{array}$ \\
\hline $1 s_{5}-2 p_{2}$ & $4,500.9772$ & $\begin{array}{r}12 \\
100 \\
6 \\
5\end{array}$ & $\begin{array}{r}-0.0238 \\
+.0197 \\
+.0368\end{array}$ & $\begin{array}{r}-.0234 \\
+.0191 \\
+.0356\end{array}$ & $\begin{array}{l}-.0236 \\
+0194 \\
+.0362\end{array}$ & $\begin{array}{r}1.3041 \\
22,211.1877 \\
1.0920 \\
1.0091\end{array}$ & $\begin{array}{l}+.1164 \\
-.0957 \\
-.1786\end{array}$ & $\begin{array}{l}524 \\
431 \\
804\end{array}$ \\
\hline $1 s_{4}-2 p_{3}$ & $4,734.1524$ & $\begin{array}{r}5 \\
100 \\
15\end{array}$ & $\begin{array}{l}-.0248 \\
+.0182\end{array}$ & $\begin{array}{l}-.0248 \\
+.0197\end{array}$ & $\begin{array}{l}-.0248 \\
+.0190\end{array}$ & $\begin{array}{r}7.328 \\
21,117.217 \\
7.133\end{array}$ & $\begin{array}{l}+.111 \\
-.084\end{array}$ & $\begin{array}{l}525 \\
398\end{array}$ \\
\hline $1 s_{s}-2 p_{0}$ & $8,231.6348$ & $\begin{array}{r}2 \\
40 \\
300 \\
5 \\
15 \\
3\end{array}$ & $\begin{array}{r}-.0371 \\
+.0288 \\
+.0478\end{array}$ & $\begin{array}{l}-.085 \\
-.042 \\
\\
+.046 \\
+.093\end{array}$ & $\begin{array}{l}-.085 \\
-.0371 \\
+.0288 \\
+.0478 \\
+.093\end{array}$ & $\begin{array}{r}5.046 \\
4.9756 \\
12,144.9209 \\
4.8784 \\
4.8504 \\
4.783\end{array}$ & $\begin{array}{l}+.125 \\
+.054 \bar{\imath} \\
-.0425 \\
-.0705 \\
-.138\end{array}$ & $\begin{array}{r}1,029 \\
450 \\
\\
350 \\
580 \\
1,136\end{array}$ \\
\hline $1 s_{5}-2 p_{7}$ & $8,409.190$ & $\begin{array}{r}6 \\
60 \\
3\end{array}$ & $\begin{array}{l}-.0437 \\
+.043\end{array}$ & $\begin{array}{l}-.041 \\
+.042\end{array}$ & $\begin{array}{l}-.0437 \\
+.043\end{array}$ & $\begin{array}{r}8.5506 \\
11,888.4888 \\
8.428\end{array}$ & $\begin{array}{l}+.0618 \\
-.061\end{array}$ & $\begin{array}{l}520 \\
513\end{array}$ \\
\hline $1 s_{5}-2 p_{8}$ & $8,819.412$ & $\begin{array}{r}40 \\
200 \\
5 \\
12\end{array}$ & $\begin{array}{r}-.0330 \\
+.0223 \\
+.0436\end{array}$ & & $\begin{array}{l}-.0330 \\
+.0223 \\
+.0436\end{array}$ & $\begin{array}{r}5.5577 \\
11,335.5153 \\
5.4866 \\
5.4593\end{array}$ & $\begin{array}{l}+.0424 \\
-.0287 \\
-.0560\end{array}$ & $\begin{array}{l}374 \\
253 \\
494\end{array}$ \\
\hline
\end{tabular}

TABLE 3.-Comparison of observations by two methods FABRY-PEROT ÉTALONS

\begin{tabular}{|c|c|c|c|c|c|c|c|}
\hline$\lambda$, air & \multicolumn{4}{|c|}{ Individual values of $\delta \lambda$} & $\begin{array}{c}\delta \lambda \\
\text { mean }\end{array}$ & $\begin{array}{l}\text { Probable } \\
\text { error }\end{array}$ & $\begin{array}{l}\text { Differences between } \\
\text { mean ralues by }\end{array}$ \\
\hline \multirow{2}{*}{$4,500.9772$} & -0.0239 & -0.0233 & -0.0238 & -0.0240 & -0.0238 & 0.0001 & 0.0004 \\
\hline & $\begin{array}{l}+.0202 \\
+.0368\end{array}$ & $\begin{array}{l}+.0209 \\
+.0379\end{array}$ & $\begin{array}{l}+.0193 \\
+.0366\end{array}$ & $\begin{array}{l}+.0185 \\
+.0358\end{array}$ & $\begin{array}{l}+.0197 \\
+.0368\end{array}$ & $\begin{array}{r}.0004 \\
\hdashline 0003\end{array}$ & $\begin{array}{l}.0006 \\
.0012\end{array}$ \\
\hline \multirow{2}{*}{$4,734.1524$} & & & -.0257 & -.0239 & -.0248 & .0006 & .0000 \\
\hline & +.0168 & +.0177 & +.0196 & +.0185 & +.0182 & .0004 & .0015 \\
\hline
\end{tabular}


TABLE 3.-Comparison of observations by two methods-Continued LUMMER-GEHRCKE PLATES

\begin{tabular}{|c|r|r|r|r|r|r|r|r|}
\hline \multicolumn{1}{|c|}{$\lambda$, air } & \multicolumn{5}{|c|}{ Individual values of $\delta \lambda$} & \multicolumn{1}{c|}{$\begin{array}{c}\delta \lambda \\
\text { mean }\end{array}$} & $\begin{array}{c}\text { Probable } \\
\text { error }\end{array}$ \\
\hline \multirow{4}{*}{$4,500.9772$} & -0.0231 & -0.0229 & -0.0238 & -0.0236 & -0.0233 & -0.0236 & -0.0234 & 0.0001 \\
& +.0195 & +.0182 & +.0194 & +.0190 & +.0196 & +.0189 & +.0191 & .0001 \\
& +.0338 & +.0350 & +.0370 & +.0358 & +.0357 & +.0361 & +.0356 & .0003 \\
& & -.0240 & -.0254 & -.0245 & & -.0254 & -.0248 & .0002 \\
& +.176 & +.0198 & +.0219 & +.0207 & & +.0184 & +.0197 & .0005 \\
\hline
\end{tabular}

A special effort was made to observe satellites of the lines, 5,570 and 5,870 A, of krypton. These lines are of particular interest because their wave length position, intensity, and origin in the term scheme entitle them to consideration as possible standards. One faint satellite has been observed for $5,570 \mathrm{~A}$. It can not be said with certainty whether $5,870 \mathrm{~A}$ is complex, the evidence from different spectrograms being somewhat contradictory. The investigation also revealed the presence of a companion to the krypton lines, 8,104 A, and has permitted the precise determination of its wave length. The significance of this line is discussed in the second paper on the first spectrum of krypton by Meggers, deBruin, and Humphreys. ${ }^{16}$

Attention should be directed to a number of earlier investigations of selected portions of the spectra of krypton and xenon, made with interferometers for the purpose of finding hyperfine structures. Gehrcke and Janicki, ${ }^{17}$ using Lummer-Gehrcke plates, examined 16 krypton lines $(4,273$ to $5,870 \mathrm{~A})$ and 42 xenon lines $(4,078$ to $6,768 \mathrm{~A})$, including all the stronger visible lines. They report all the krypton lines sharp, especially 5,570 and 5,870 A.

Of the xenon lines examined two were found to be complex, 4,501. and $4,734 \mathrm{~A}$. The analysis of the patterns by Gehrcke and Janicki is as follows:

4, $734.30\left\{\begin{array}{cc}\delta \lambda & \text { Intensity } \\ -0.0254 & \frac{1}{10} \\ +0.0176 & \frac{1}{3}\end{array}\right.$
$4,501.13\left\{\begin{array}{lc}-0.043 & \frac{1}{20} \\ -0.0225 & \frac{1}{3} \\ +0.0306 & \frac{1}{5}\end{array}\right.$

We are unable to agree with this analysis of $4,501 \mathrm{~A}$ as to position and intensity of the three satellites. In view of the agreement

1 'Meggers, deBruin, Humphreys, B. S. Jour. Research. (In press.)

17 Gehrcke and Janicki, Ann. der Physik, 81, p. 314; 1926. 
between our results, obtained with Fabry-Perot étalons and LummerGehrcke plates, we feel certain that the results of Gehrcke and Janicki for 4,501 A are in error.

Other investigations are confined to the examination of the yellow and green lines of krypton. Perard ${ }^{18}$ studied the lines 5,570 and 5,870 A, with a Michelson interferometer, and reported that each has two close satellites. Weber, ${ }^{19}$ at the Reichsanstalt, examined three krypton lines 5,570,5,649, and 5,870 A, and proposed the yellowgreen line 5,649 as a primary standard. A more recent report from the Reichsanstalt ${ }^{20}$ states that the line 5,649 is sharp, but that 5,570 has five satellites, and 5,870 two very close faint satellites.

The hyperfine structures in the rare gases are supposed to be due to isotopes. Investigations of the $\mathrm{Ne}$ lines by Hansen, ${ }^{21}$ by Nagaoka and Mishima, ${ }^{22}$ and by Thomas and Evans ${ }^{23}$ indicate that all the lines due to $s p$ combinations have a single satellite on the short wave length side of from $1 / 10$ to $1 / 4$ the intensity of the main component. This is to be expected in the case of an element having two isotopes. There is some recent evidence for a $\mathrm{Ne}$ isotope of atomic weight 21 , but the amount is so small that any observed hyperfine structures would be expected to arise from $\mathrm{Ne} 20$ and $\mathrm{Ne} 22$ only. Although they have not been able to predict the exact satellite separations on theoretical grounds, Thomas and Evans have shown that the ratio $\frac{\delta \nu}{\nu}$ has a constant value for combinations with each of the low $s$ levels. In the present investigation no definite regularities have been found either in the values of $\delta \nu$ or $\frac{\delta \nu}{\nu}$. It may be seen also that only a relatively small number of the $s p$ combinations show structures. In the krypton spectrum most of the complex lines are combinations with $s_{2}$, or in the present standard notation ${ }^{1} \mathrm{P}_{1}$, whereas in the case of xenon, five of the six observed complex lines involve $s_{5}$; that is, ${ }^{3} \mathrm{P}_{2}$ combinations. No definite analogies can be traced. It is likely that the xenon lines involving $s_{5}$ all have a close pattern of one satellite on the short wave length side and two on the long with possibly others farther removed as shown by $8,231 \mathrm{~A}$. The outer satellites of $8,819 \mathrm{~A}$ are shown, but too faint for measurement on some of the plates. The resolution of the patterns of 4,193 and 8,409 $\mathrm{A}$ is imperfect.

Since krypton and xenon are reported to have 6 and 9 isotopes, respectively, the hyperfine structures would be expected to be more complicated than those in neon. We would expect all lines due to $s p$ combinations to be complex. A possible interpretation of the hyperfine structures in mercury has recently been suggested by Schüler ${ }^{24}$ according to which the nuclear moment of the isotopes of odd atomic weight may be responsible for the resolved structures, whereas the structures due to the even isotopes are too narrow to permit the resolution of the heavy central component. In support of this he gives the relative proportions of the isotopes and notes that those of odd atomic weight comprise about 30 per cent of the total mass,

18 Perard, Comp. Rend., 176, p. 1060; 1923.

1s Weber, Physik. Zeit., 29, p. 233; 1928.

2c Bureau of Standards Yearbook for 1930, p. 33

21 Hansen, Nature, 119, p. 239; 1927.

22 Nagoka and Mishima, Imp. Acad., Tokyo Proc., 5, p. 200; 1929

23 Thomas and Evans, Phil. Mag., 10, p. 128; 1930.

a Schüler, Naturwissenschaften, i3, p. 895; 1930. 
and further that the sum of the intensities of the satellites is between 25 and 32 per cent of the total intensity of a given pattern. These considerations can scarcely apply to neon because the scarcity of isotope 21 has been mentioned, but they may apply to krypton in which isotope 83 is fourth in order of abundance, and with still greater force to xenon in which isotopes 129 and 131 are first and third, respectively.

The imperfect resolution of some of the patterns and the strong probability that an additional number, if not all, of the strong lines are complex makes it advisable to continue the investigation, with the conditions of emission controlled so as to increase the sharpness of the lines and with still higher resolving power.

Washington, June 10, 1931. 